\title{
Selection of Solar Simulator for Solar Dynamic Ground Test
}

Carol M. Tolbert

Lewis Research Center

Cleveland, Ohio

Prepared for the

29th Intersociety Energy Conversion Engineering Conference cosponsored by SAE, ACS, AIAA, ASME, IEEE, and AIChE Monterey, California, August 7-12, 1994

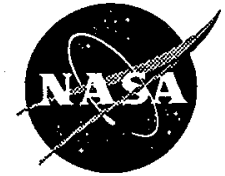

National Aeronautics and Space Administration

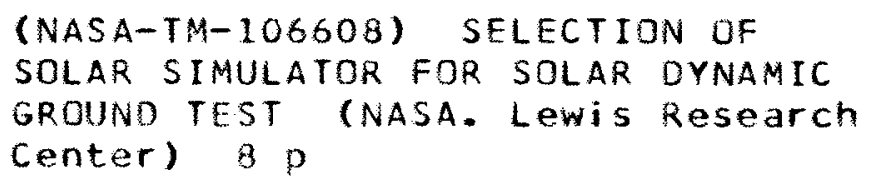

Unclas 


\title{
SELECTION OF SOLAR SIMULATOR FOR SOLAR DYNAMIC GROUND TEST
}

\author{
CAROL M. TOLBERT \\ Power Technology Division \\ NASA Lewis Research Center \\ Cleveland, Ohio
}

\begin{abstract}
The $2 \mathrm{kWe}$ Solar Dynamic (SD) Ground Test Demonstration (GTD) experiment will be conducted in 1995 at NASA Lewis Research Center (LeRC). This solar dynamic power system test will be conducted in a simulated space environment and will require an artificial sun. To address the solar simulator requirements for the GTD, Arnold Engineering Development Center (AEDC) was hired under contract to review and visit four existing solar simulator facilities. The four facilities included, AEDC's Mark 1 Chamber, NASA-JSC Chamber A, AEDC's 12V Chamber, and NASA-JPL Space Simulator Chamber. Two design concepts were considered following several months of evaluating existing solar simulator facilities throughout the United States. To satisfy system requirements for the SD GTD experiment, the solar simulator needs to provide a uniform light flux to the SD concentrator, provide the light within a subtense angle of one degree, and provide an intensity of one solar constant $\left(1.37 \mathrm{~kW} / \mathrm{m}^{2}\right)$ at airmass zero. Most solar simulators are designed for supplying heat loads to spacecraft where a cone angle as large as 3 degrees is acceptable. It was also concluded that a solar simulator, such like these considered in the AEDC study, would require major facility modifications for NASA LeRC and result in significant impacts to the program. The advanced solar simulator concept developed by NASA LeRC will meet the system requirements for the SD GTD experiment. Since SD GTD solar simulator requirements could not be addressed by existing simulator, an advanced concept was considered.
\end{abstract}

\section{INTRODUCTION}

The $2 \mathrm{kWe}$ Solar Dynamic Ground Test Demonstration program was initiated by the NASA Office of Aeronautics and Space Technology and is managed by NASA Lewis Research Center.' The primary goal of the SD GTD program is to conduct a ground-based test of a solar dynamic space power system which includes energy storage in an environment simulating a representative low earth orbit. ${ }^{2}$

In a solar dynamic power system, a solar concentrator collects and focuses the sun's light into the aperture of a heat engine such as a closed Brayton cycle system. ${ }^{3}$ In such a system, a gaseous working fluid is heated by solar energy in the heat receiver, and converted to electricity by a power conversion unit. $^{3}$

SD technologies have been developed by NASA programs during the past 30 years and are available for near Earth orbit. ${ }^{2}$ However, NASA was faced with the challenge of providing a solar simulator to ground test the solar dynamic system.

The requirements for the solar simulator were based on the requirements for the solar dynamic system to be tested.' The solar simulator must illuminate the concentrator so that it can focus the light to the receiver aperture to power the SD system. To properly test the SD system, the simulator must be capable of providing at least as much power as will be provided by the sun in low Earth orbit. $^{5}$ 


\section{BACKGROUND}

Arnold Engineering Development Center (AEDC) was hired by LeRC to perform a solar simulator study based on its experience in the development and use of solar simulators. Under a grant to the Cleveland State University - The Advanced Manufacturing Center (CSU-AMC) conducted an experimental investigation of the advanced lamp system. LeRC also conducted in-house efforts to support the project and directed the efforts of AEDC and CSU-AMC.

AEDC reviewed and visited four existing solar simulator facilities. NASA Johnson Space Center (JSC) Chamber A and AEDC Mark 1 Chamber represented on-axis solar simulator. NASA Jet Propulsion Laboratory (JPL) and AEDC 12V chamber represented off-axis type simulators.

CSU-AMC conducted an experiment to demonstrate the advanced optics developed at LeRC. The advanced optics were based on a $1 / 3$ geometric scale aluminum collector and plexiglass lens module similar to the lamp module designed for the LeRC simulator facility. The objective of the experiment was to achieve acceptable uniformity for the SD test and to capture more of the available light energy than is currently possible and distribute the energy more evenly across the diameter of the concentrator.

\section{SOLAR SIMULATION TERMS}

Important technical terms related to the NASA LeRC requirements are detailed in this section, and include: subtense angle, beam diameter, uniformity, irradiance and collimation.

Subtense Angle - The solar beam subtense angle is that angle subtended by the maximum dimension of the apparent source at an arbitrary point on the test specimen. It is the angle from the viewer's eye looking back to the light source (sun). That angle is defined by the diameter of the light source which for the sun is $139 \times 10^{+4} \mathrm{~km}$ diameter divided by the distance from the sun which is $149.6 \times 10^{+6} \mathrm{~km}$, resulting in 0.00929 radians. The solar simulator for this ground test has an apparent diameter of $30.5 \mathrm{~cm}$ and is $17.25 \mathrm{~m}$ away resulting in 0.0177 radians. The subtense angle for the ground test is twice as large as the sun but is sufficiently small to satisfy the ground test (Fig. 1).

Beam Diameter - Refers to the diameter of the pseudo sun on the concentrator. The test article requires a uniform $4.8 \mathrm{~m}$ diameter beam.

Uniformity - Refers to the uniformity of light flux incident on a spherical control surface at a distance of $17.25 \mathrm{~m}$ from the pseudo sun. The vertex of the solar dynamic concentrator is on this control surface.

Irradiance or Radiant Flux Density - Refers to the amount of radiant power per unit area that impinges on a surface.

Collimation - Refers to parallel light. Many solar simulators use collimating mirrors to produce a parallel light beam. For this ground test experiment, the need for a collimating mirror was eliminated by making subtle changes to the shape of the solar dynamic concentrator.
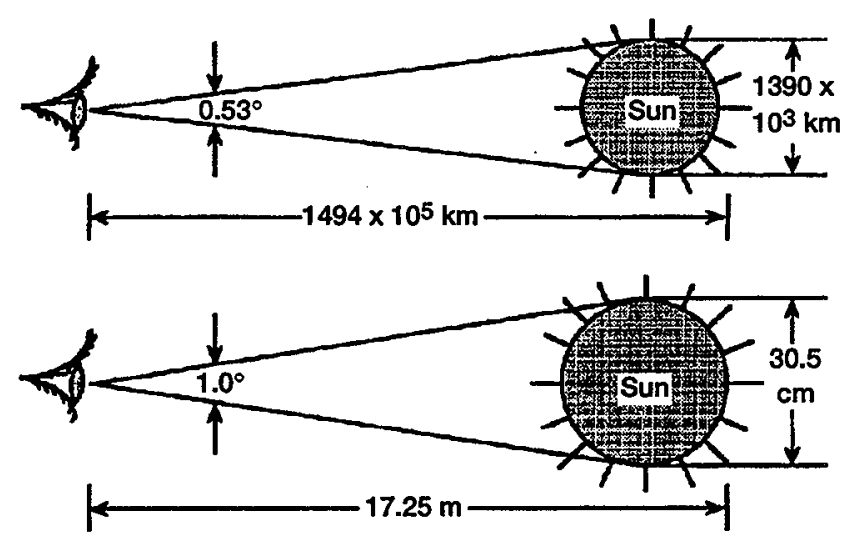

Figure 1.-Subtense angle of the sun and subtense angle for SD GTD.

\section{SOLAR DYNAMIC REOUIREMENTS FOR THE LIGHT SOURCE}

A solar simulator is required for the $2 \mathrm{kWe} \mathrm{SD}$ Ground Test Demonstration. The required energy source must supply simulated solar flux to the concentrator of the solar dynamic system in order to supply energy into the solar receiver. The light energy is converted to thermal energy in the heat receiver, converted to mechanical work by a turbine, and ultimately converted to electrical power by an alternator. To provide energy to the system, the solar simulator must provide to the concentrator a uniform light beam of $4.78 \mathrm{~m}$ in diameter, provide the light within a subtense angle of one degree, and provide an intensity of one solar constant $\left(1.37 \mathrm{~kW} / \mathrm{m}^{2}\right)$ at air-mass zero.

The SD system requires a subtense angle close to that of the sun, $\pm 0.25^{\circ}$. Since it is difficult to provide a subtense angle of 0.25 degrees on the ground, a subtense angle of $\pm 0.5^{\circ}$ will suffice for this demonstration (Fig. 2). The larger subtense angle requires an increase in the size of the solar 


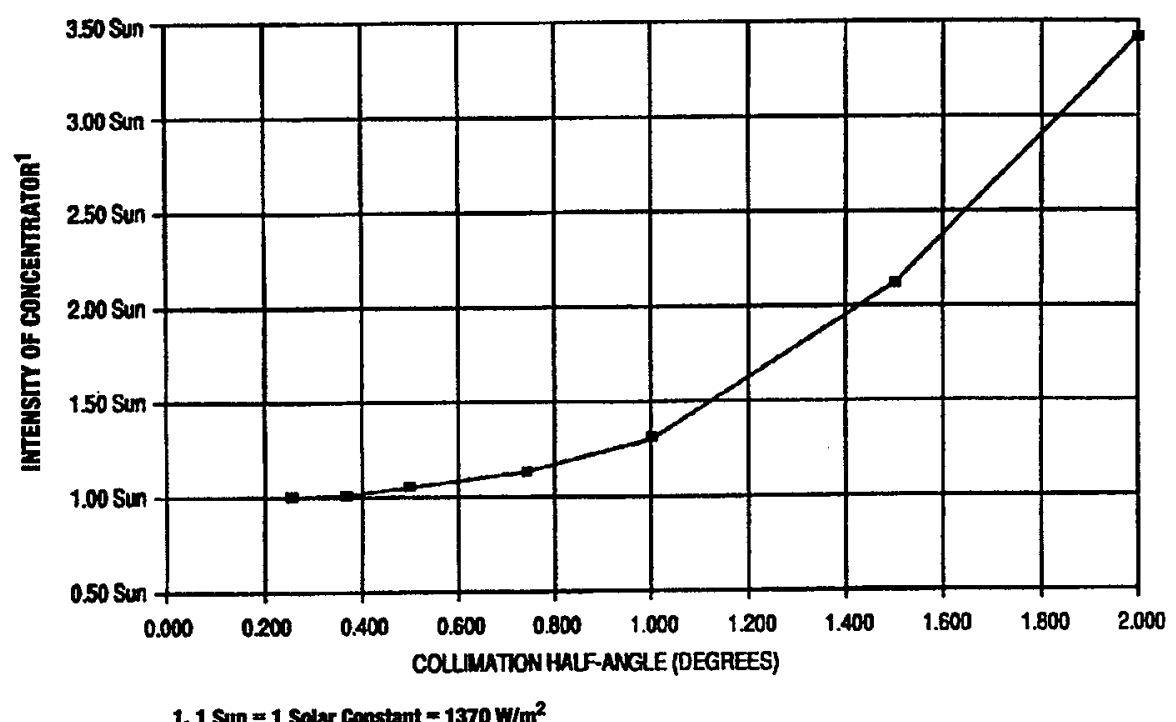

Figure 2.-Intensity required to maintain energy into the receiver with increasing subtense angle.

dynamic receiver aperture that the light is concentrated into and also results in more energy loss at the receiver aperture.

Xenon lamps chosen for many simulators have a $5900 \mathrm{~K}$ blackbody curve spectral distribution which only fairly approximates the blackbody curve of the sun (Fig. 3). The spectral distribution of the light from the simulator does not need to be an exact match to the sun because the SD system uses the heat from the light and an aluminum reflective surface that provides near equal reflectance at all wavelengths above 3.0 microns.

The solar simulator must also provide a uniform intensity over the reflective surface to ensure uniform heating within the receiver. The target value of $\pm 10 \%$ over an area of $0.093 \mathrm{~m}^{2}$ was chosen. Uniformity over the reflective surface refers to an average percentage over the test volume with a $0.093 \mathrm{~m}^{2}$ detector for macro-uniformity and a $0.064 \mathrm{~m}^{2}$ detector for micro-uniformity.

The solar simulator is supported by three major subsystems: air and water cooling systems, electrical system, and instrumentation and controls. A closed-loop deionized water system is required for cooling the xenon lamps. The water system is deionized to prevent shocks and provide electrical power to the lamps through the lamp cooling lines. Regular filtered water is required for the lamp collectors, shutter, and water cooled housing. The lamp housing protects personnel from the light beam and possible lamp explosion hazards. The air cooling system is required to provide additional cooling to the lamp housing, the lamps, the lamp collectors and the shutter. In addition, this system will remove any ozone generated from the lamps. Power systems are required for the water and air systems as well as the lamps.

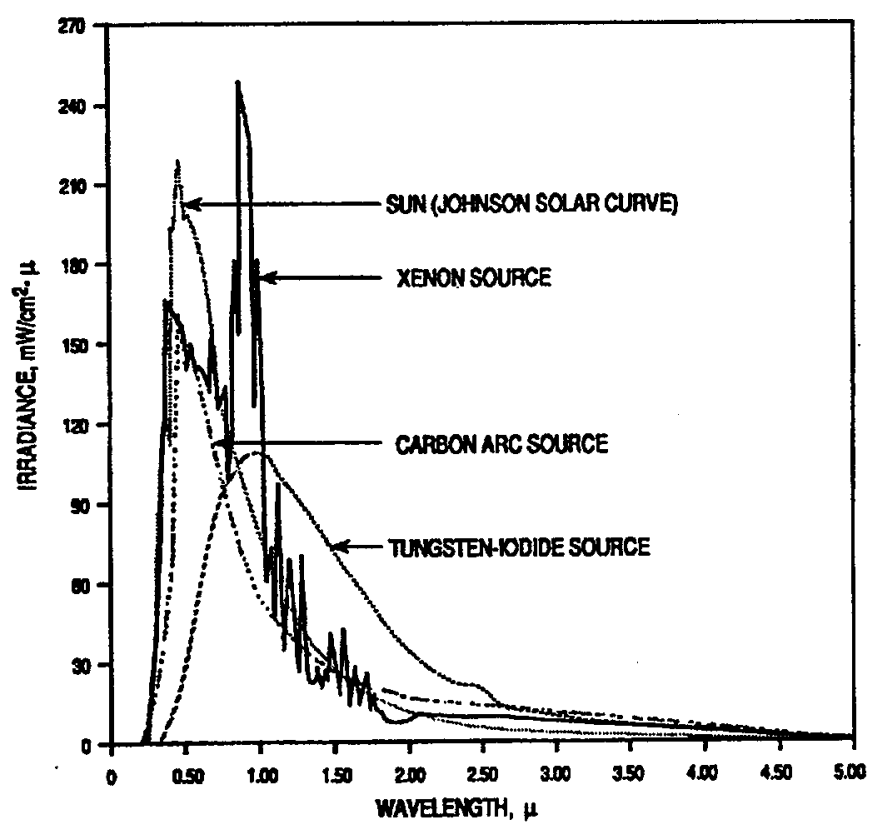

Figure 3.-Comparison of carbon arc, xenon, and tungsten-iodine sources with solar spectrum. 


\section{SOLAR SIMULATTORS REVIEWED BY AEDC}

Under contract to NASA Lewis, AEDC reviewed and visited four existing solar simulators. AEDC's Mark 1 Tungsten-Iodine system and NASA-JSC Chamber A Xenon Cassegrain system represented on-axis solar simulator and AEDC's $12 \mathrm{~V}$ chamber and NASA-JPL $25 \mathrm{ft}$. Space Simulator chamber represented the off-axis solar simulator. Table 1 lists the parameters of various solar simulator facilities and the proposed NASA LeRC simulator based on the AEDC study.

\section{AEDC Mark 1}

The AEDC Mark 1 chamber is located at Arnold Air Force Base, Tennessee.

The vertical chamber is $12.8 \mathrm{~m}$ in diameter by $25.0 \mathrm{~m}$ high cylindrical, stainless steel, vacuum chamber. Solar simulation tests are conducted with onaxis Tungsten-Iodine lamp.

The Mark 1 solar simulator consists of a large array of Tungsten-Iodine lamps with water-cooled collimating tubes arranged in a matrix that is enclosed in a support frame suspended from the top of the chamber. The simulator can produce a continuous variable radiant flux from 0 to 1.1 solar constants into the test volume with a micro-uniformity of \pm 3 percent. The uniformity was measured with a $0.0254 \mathrm{~m}$ diameter sensor over the entire test volume. The subtense angle is \pm 4 degrees as measured by AEDC. The blackbody spectrum of the lamps operating at 120 volts is $3000 \mathrm{~K}$.

An on-axis Tungsten-Iodine simulator system adapted to the LeRC Tank 6 facility would consist of a lamp module containing 430 lamps and collimating tubes in a circular array of approximately 17 $\mathrm{ft}$. diameter. The maximum radiation output of the on-axis system would be 1.1 solar constants. The subtense angle would be \pm 4 degrees. The subtense could be improved by extending the length of the collimation tubes, however, the radiation output would decrease. Because of the limitations of these parameters, the Tungsten-Iodine system would require significant modifications to the existing NASA facility and unacceptable schedule delays.

\section{NASA - Lundon B. Johnson Space Center}

\section{Chamber A}

The NASA-JSC Chamber $A$ is located at the Lyndon B. Johnson Space Center in Houston, Texas. The JSC Chamber can be used for vacuum, solar, heat-sink and other thermal space environment testing.

The vertical chamber is $19.8 \mathrm{~m}$ in diameter by $36.5 \mathrm{~m}$ high. Thermal testing is provided with on- axis, cassegrain optics, xenon lamp solar simulator. The on-axis solar simulator includes individual cassegrainian mirrors, hexagonally shaped, mounted on the vertical chamber wall in a honeycomb configuration. The source for each hexagonal mirror consist of a xenon lamp module, integrating lens and a cassegrain reflective/refractive optical system. The lamp module contains a $20 \mathrm{~kW}$ xenon lamp, lamp collector and a spectral filter. The subtense angle is \pm 1.5 degrees with a maximum of 1.2 solar constants.

The JSC on-axis xenon system adapted to the LeRC Tank 6 facility would consist of lamp modules in a hexagonal configuration of approximately $4.9 \mathrm{~m}$ diameter. Construction of a new $0.012 \mathrm{~m}$ diameter flat aluminum end cap would be required. The lamp modules would be stacked on a support structure frame independent of the chamber end cap. A person-rated lift would be required to install each module. Since the subtense angle, cost, and other parameters associated with the JSC chamber could not meet the SD GTD program requirements and goals, the on-axis, xenon, cassegrain system was not considered.

\section{AEDC 12V Chamber}

The Arnold Engineering Development Center (AEDC) $12 \mathrm{~V}$ Chamber is located at Arnold Air Force Base, Tennessee. The chamber was specifically designed for thermal balance testing of components and space vehicles.

AEDC's vertical chamber is $3.6 \mathrm{~m}$ in diameter and $10.6 \mathrm{~m}$ high and is constructed of 304-type stainless steel for low outgassing. The lamp housing contains seven $20 \mathrm{~kW}$ xenon lamps and ellipsoidal collectors.

The AEDC solar simulator will produce a continuous variable radiant flux of 0 to 2.3 solar constants. The solar test volume area has a $\pm 5 \%$ micro uniformity. The subtense angle is \pm 1.8 degrees.

The AEDC solar simulator was not acceptable for the NASA LeRC facility based on LeRC Tank 6 physical dimensions. Additional length would be required to accommodate a chamber at Lewis similar to the $12 \mathrm{~V}$ Chamber at AEDC resulting in significant cost. If an extension to the chamber were approved, the impact to the overall program schedule would be prohibitive. Therefore, the AEDC solar simulator was determined not to be acceptable for NASA LeRC. 
NASA-JPL $25 \mathrm{ft}$. Space Simulator

The NASA-JPL $25 \mathrm{ft}$. Space Simulator is located at the Jet Propulsion Laboratory, Pasadena, California. The chamber can provide testing such as thermal modeling, flight qualification tests, spinbalance tests and vacuum coating of large optical components. The test volume is $6.1 \mathrm{~m}$ in diameter by $7.6 \mathrm{~m}$ high. The chamber utilizes an off-axis xenon lamp solar simulator.

The JPL stainless steel cylindrical vessel is $8.2 \mathrm{~m}$ diameter by $26 \mathrm{~m}$ high. The chamber utilizes an offaxis xenon lamp solar simulator. The JPL solar simulator is similar in design to AEDC's $12 \mathrm{~V}$ solar simulator. The off-axis xenon lamp system provides $2.6 \mathrm{~m}$ diameter test beam with \pm 1.3 subtense angle. The overall impact to schedule and costs made implementing a solar simulator similar to the JPL facility for NASA LeRC unacceptable.

\section{ADVANCED SOLAR SIMULATOR}

To define the solar simulator for the SD GTD, NASA initiated a study. The study was conducted by the Lewis Research Center Engineering Directorate and Cleveland State University (CSU) Advanced Manufacturing Center (AMC) under grant.

CSU/AMC investigated an advanced lamp module reflector which would provide uniform illumination to a turning mirror thereby eliminating the need for a mixing lens in the solar simulator. CSU/AMC built and tested a scale model of the advanced lamp module. They compared the observed magnitude and distribution of radiant power to that predicted by theory, and verified the capability of the advanced module to provide the power, uniformity and subtense angle necessary for the SD demonstration. CSU/AMC also verified that the parameters of the new design model could scale up a full size solar simulator. The new design was developed to satisfy the requirezments of the SD demonstration. This improved performance resulted from the following key features: (1) elimination of the collimating mirror commonly used in solar simulators to transform the diverging beam into a parallel beam, (2) a redesigned lamp module that has increased efficiency, and (3) the use of a segmented reflective surface to combine beams from several individual lamp modules at the pseudosun. Each segment of this reflective surface has complex curvature to control the distribution of light. ${ }^{4}$

Figure 4 shows the advanced solar simulator in detail with a table listing the characteristics. The advanced solar simulator does not include a collimating mirror resulting in a less complex system. Figure 5 provides a comparison between the ad- vanced solar simulator design concept and the classical solar simulator design. Most importantly, the advanced solar simulator represents substantial savings in cost from 5 million dollars for most existing simulators to between 2-3 million dollars for the advanced system. Figure 6 is a drawing of the advanced solar simulator in Tank 6 . Facility operating costs are lower as a result of using a lower input power which also means less cooling of the system. A cost savings may be realized with respect to the lamp house volume space. The advanced concepts includes 9 xenon lamps instead of 19 or more lamps used by most simulators. Fewer lamps also means less energy consumed. Each lamp is powered by an individual power supply. Instrumentation is required to monitor the status of the simulator and related systems instrumentation. Instrumentation is required to remotely align mirror segments. Much of the instrumentation monitoring requirement will be personal computer based (Fig. 4 \& 5). This advanced solar simulator concept will advance the state-of-the-art in precision optics and minimize costs associated with the $2 \mathrm{kWe} \mathrm{SD} \mathrm{GTD.} \mathrm{In}$ addition to monetary savings, NASA Lewis would have test facility with the potential for growth in the future. This facility could serve as a test bed for future static and dynamic power systems applications.

\section{CONCLUSION}

As a result of AEDC's study, it was determined that available solar simulator facilities could not satisfy test requirements for the SD GTD and attempts to duplicate existing facilities at LeRC would result in unacceptable costs and schedule impacts to the program.

The SD GTD requirements for an energy source to satisfy the flux and subtense angle parameters were key in LeRC's decision to test and develop an advanced lamp module. The efficiency of the advanced lamp module will result in a simulator that is lower in cost, requires less facility space, and has increased efficiency compared with simulators that currently exist.

\section{ACKNOWLEDGEMENT}

I wish to acknowledge the support of Dr. Henry Brandhorst (NASA Lewis), Dr. Donald Jaworske (NASA Lewis), and Mr. Kent Jefferies (NASA Lewis).

Prepared for the 29th Intersociety Energy Conversion Engineering Conference, Monterey, California, August 7-12, 1994. 


\section{REFERENCES}

1. James E. Calogeras, "The Ground Testing of a 2 kWe Solar Dynamic Space Power System," Proc. 27th IECEC; 1992.

2. Richard K. Shaltens, Robert V. Boyle, "Overview of the Solar Dynamic Ground Test Demonstration Program," Proc. 28th IECEC; 1993.

3. T. L. Labus, R. R. Secunde and R. G. Lovely, "Solar Dynamic Power for Space Station Freedom," Space Power, Vol. No. 5, 1/21/89.

4. Kent S. Jefferies, "Solar Simulator for Solar Dynamic Space Power System Testing," Proc. for ASME International Society of Mechanical Engineers, March, 1994.

5. A. Pint, R. Bierling, C. Castle, "Uniform Magnification Lamp Module Evaluation", Cleveland State University-Advanced Manufacturing Center, AMC-1002, NCC 3-143, October 1992.

6. Castle, John A., "Terms, Symbols and Units," Handbook of Solar Simulation for Thermal Vacuum Testing, Institute of Environmental Sciences, 1968.

7. K. Jefferies, "Solar Dynamic Power System Development for Space Station Freedom", RP1310, May 1993.

8. Capt W. C. Phipps, C. K. Holt, "Tank 6 Test Facility Solar Simulator Project Plan", Arnold Engineering Development Center, United States Air Force Material Command, August 1992.

9. Jefferies, K. S., "Ray Tracing Optical Analysis of Offset Solar Collector for Space Station Solar Dynamic System. Proceedings of the 23rd Intersociety Energy Conversion Engineering Conference," Vol. 4, ASME, 1988.

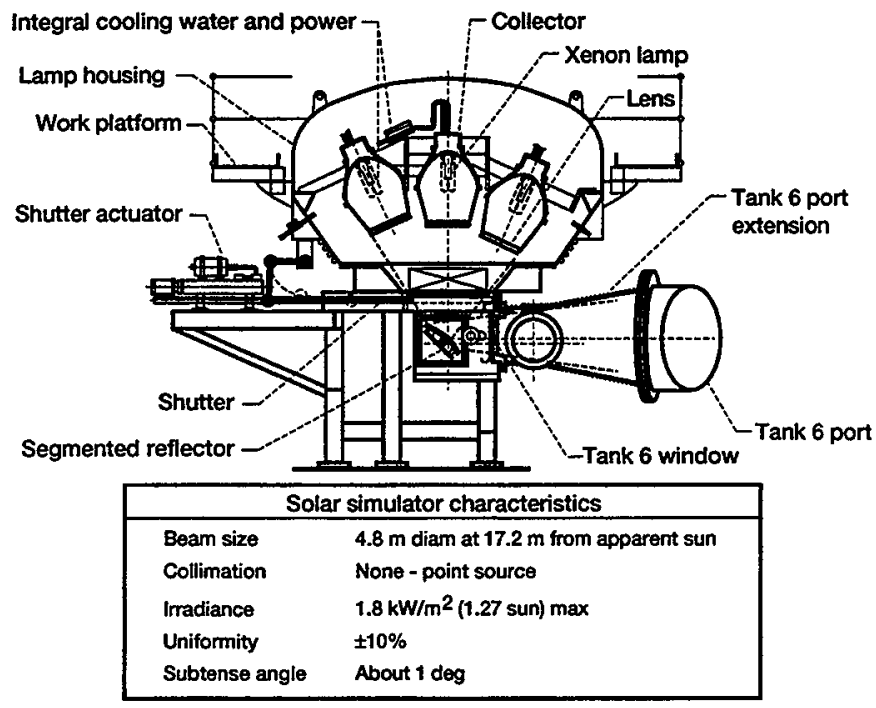

Figure 4.-Drawing of advanced solar simulator.
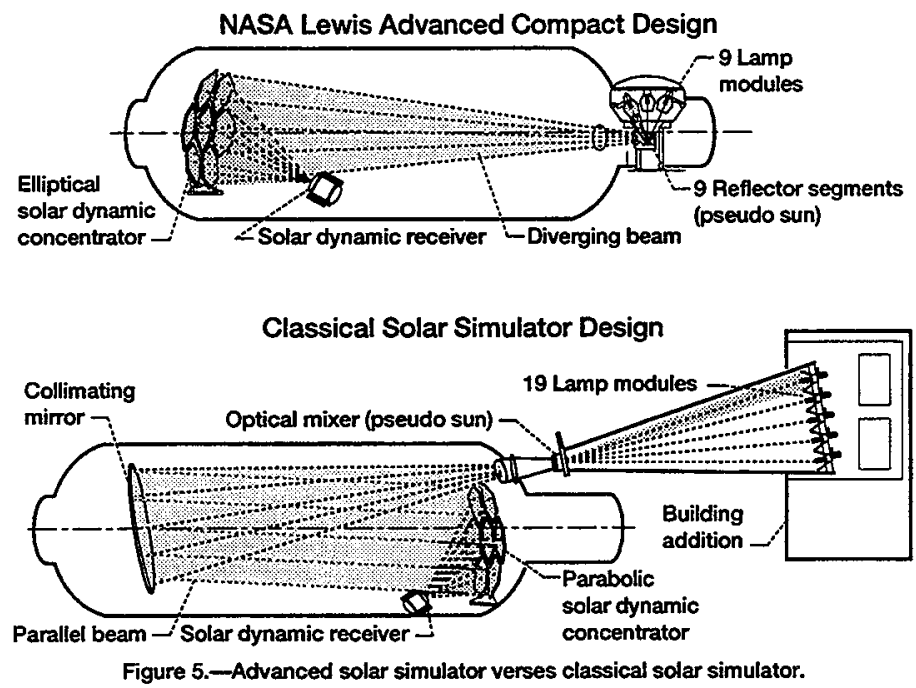

\begin{tabular}{|c|c|c|c|c|c|}
\hline Eachirr & CHAMBER STZE & SUPTENSE ' & BEAM & MTENSTY 2 & LNAFORUTII \\
\hline AEDCAMARK 1 SYSTES & $244 \mathrm{~m} \times 128 \mathrm{~m}$ & 80 & $5.48 \mathrm{~m} \times 7.62 \mathrm{~m}$ & up to 1.1 & $+3 x^{3}$ \\
\hline MASA-JSC STSTEM & $36.6 \mathrm{~m} \times 19.8 \mathrm{~m}$ & 30 & e 40" Hex & up to 12 & $\begin{array}{l}+10 x^{3} \\
+1.5 x^{4}\end{array}$ \\
\hline AEDC-12V SYSTEU & $10.7 \mathrm{~m} \times 3.66 \mathrm{~m}$ & 3.6 & $246 \mathrm{~m} \mathrm{DKa}$ & up to 23 & $465 x^{3}$ \\
\hline MASA-JPL 25FT. SYSTEM & $25.9 \mathrm{~m} \times 8.23 \mathrm{~m}$ & 26 & $4.57 \mathrm{~m} \mathrm{Oh}$ & up to 2.3 & $+5 \%^{3}$ \\
\hline 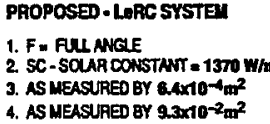 & $\begin{array}{l}7.62 \mathrm{~m} \times 21.9 \mathrm{~m} \\
\mathrm{~m}^{2}\end{array}$ & 1.0 & $4.57 \mathrm{~m} \mathrm{Dia}$ & up to 1.8 & $+5 \%^{3}$ \\
\hline
\end{tabular}

Table 1.-Summary of solar simulator parameters. 
Public reporting burden for this collection of information is estimated to average 1 hour per response, including the time for reviewing instructions, searching existing data sources, gathering and maintaining the data needed, and completing and reviewing the collection of information. Send comments regarding this burden estimate or any other aspect of this Davis Highway, Suite 1204, Arlington, VA 22202-4302, and to the Office of Management and Budget. Paperwork Reduction Project (0704-0188), Washington, DC 20503.

\begin{tabular}{|l|l|r|}
\hline 1. AGENCY USE ONLY (Leave blank) & $\begin{array}{c}\text { 2. REPORT DATE } \\
\text { August } 1994\end{array}$ & $\begin{array}{r}\text { 3. REPORT TYPE AND DATES COVERED } \\
\text { Technical Memorandum }\end{array}$
\end{tabular}

4. TITLE AND SUBTITLE

5. FUNDING NUMBERS

Selection of Solar Simulator for Solar Dynamic Ground Test

6. AUTHOR(S)

WU-233-03-0B

Carol M. Tolbert

7. PERFORMING ORGANIZATION NAME(S) AND ADDRESS(ES)

8. PERFORMING ORGANIZATION REPORT NUMBER

National Aeronautics and Space Administration

Lewis Research Center

E-8889

Cleveland, Ohio 44135-3191

9. SPONSORING/MONITORING AGENCY NAME(S) AND ADDRESS(ES)

10. SPONSORING/MONITORING AGENCY REPORT NUMBER

National Aeronautics and Space Administration

Washington, D.C. 20546-0001

NASA TM-106608

11. SUPPLEMENTARY NOTES

Prepared for the 29th Intersociety Energy Conversion Engineering Conference cosponsored by SAE, ACS, AIAA, ASME, IEEE, and AIChE, Monterey, California, August 7-12, 1994. Responsible person, Carol M. Tolbert, organization code $5490,(216) 433-6167$.

12a. DISTRIBUTION/AVAILABILITY STATEMENT

12b. DISTRIBUTION CODE

Unclassified - Unlimited

Subject Categories 20 and 74

13. ABSTRACT (Maximum 200 words)

The $2 \mathrm{kWe}$ Solar Dynamic (SD) Ground Test Demonstration (GTD) experiment will be conducted in 1995 at NASA Lewis Research Center (LeRC). This solar dynamic power system test will be conducted in a simulated space environment and will require an artificial sun. To address the solar simulator requirements for the GTD, Arnold Engineering Development Center (AEDC) was hired under contract to review and visit four existing solar simulator facilities. The four facilities included, AEDC's Mark 1 Chamber, NASA-JSC Chamber A, AEDC's 12V Chamber, and NASA-JPL Space Simulator Chamber. Two design concepts were considered following several months of evaluating existing solar simulator facilities throughout the United States. To satisfy system requirements for the SD GTD experiment, the solar simulator needs to provide a uniform light flux to the SD concentrator, provide the light within a subtense angle of one degree, and provide an intensity of one solar constant $\left(1.37 \mathrm{~kW} / \mathrm{m}^{2}\right)$ at airmass zero. Most solar simulators are designed for supplying heat loads to spacecraft where a cone angle as large as 3 degrees is acceptable. It was also concluded that a solar simulator, such like these considered in the AEDC study, would require major facility modifications for NASA LeRC and result in significant impacts to the program. The advanced solar simulator concept developed by NASA LeRC will meet the system requirements for the SD GTD experiment. Since SD GTD solar simulator requirements could not be addressed by existing simulator, an advanced concept was considered.

14. SUBJECT TERMS

Solar simulator; Subtense angle; Dynamic; Solar power system

17. SECURITY CLASSIFICATION OF REPORT

Unclassified
18. SECURITY CLASSIFICATION OF THIS PAGE

Unclassified
19. SECURITY CLASSIFICATION OF ABSTRACT Unclassified 